\title{
Scaling of infiltration rate using the similar media theory and dimensional analysis
}

\section{Henry Oppong Tuffour a,*, Mensah Bonsu a, Awudu Abubakari a, Janvier Bigabwa Bashagaluke a,b, Murphy Acheampong Opoku c, Jimmy Clifford Oppong d}

\author{
a Department of Crop and Soil Sciences, Kwame Nkrumah University of Science and Technology, Kumasi, Ghana \\ b Catholic University of Bukavu, Democratic Republic of Congo \\ c Palm Institute of Strategic Leadership, Ghana \\ d Institute of Environmental and Sanitation Studies, University of Ghana, Legon - Accra, Ghana
}

\section{Article Info}

Received : 18.01 .2018

Accepted : 11.07.2018

\begin{abstract}
The infiltration rates of variable soils were scaled using factors derived from the steady state infiltrability $\left(K_{o}\right)$ and the saturated hydraulic conductivity $\left(K_{s}\right)$ based on the similar media theory and dimensional analysis. Infiltration rates were successfully scaled when the characteristic scaling infiltration rate equations were formulated through combination of the similar media theory and dimensional analysis. This study disproved the earlier notion that to successfully scale variable infiltration measurements, both sorptivity and steady state infiltrability were required. Thus, the study revealed that using the saturated hydraulic conductivity as a substitute for the steady state infiltrability could predict and scale infiltration rates more accurately. The study further highlighted the importance of the scaling factor $(\alpha)$ in any characteristic equation supposedly to have been developed from the similar media theory. Invariably, the ability of any characteristic scaling equation containing no scaling factor to scale variable infiltration measurements successfully could be fortuitous and not evolved from the similar media theory.

Keywords: Dimensional analysis, saturated hydraulic conductivity, scaling factor, similar media, steady state infiltrability.
\end{abstract}

(C) 2018 Federation of Eurasian Soil Science Societies. All rights reserved

\section{Introduction}

Infiltration is an important soil hydrological process useful in irrigation systems design, erosion and runoff modeling of a watershed and general water budget studies (Tuffour and Bonsu, 2015). Since soils exhibit a high degree of variability in both space and time, soil physical properties alone cannot be used to evaluate the hydrological response to a watershed, especially in the tropics where soils may exhibit natural spatial variability due to uncontrollable factors such as worm and ant holes, dead root channels and pore, as well as inconsistent soil management practices (Tuffour et al., 2016). Thus, invariably, heterogeneity is a general problem in soils; management, topographic as well as pedogenic factors may all contribute to soil heterogeneity. Besides, spatial variability in hydraulic properties and hydrologic processes continue to be an unresolved problem, which has attracted research attention of past and present scientists (e.g. Sharma and Luxmoore, 1979; Wu and Pan, 1979; Berndtsson and Larson, 1987; Sharma et al., 1987; Bonsu, 1997; Wu et al., 1999; Tuffour et al., 2014).

Differences in soil texture and structure may reflect in the extent of spatial variability of tropical soils. Bonsu and Laryea (1989) noted that soil texture and structure significantly influenced the hydraulic behavior of an Alfisol in the semi-arid tropics in India. Bonsu and Lal (1982) also recognized anisotropic characteristics in

\footnotetext{
${ }^{*}$ Corresponding author.

Department of Crop and Soil Sciences, Kwame Nkrumah University of Science and Technology, Kumasi, Ghana

Tel.: +233208542308

e-ISSN: 2147-4249

E-mail address: hotuffour@agric.knust.edu.gh DOI: $10.18393 /$ ejss.450299
} 
horizontal and vertical hydraulic properties of an Alfisol in Nigeria. The implication is that this combined vertical and horizontal spatial variability of soil hydraulic properties may play a negative influence on the response and sensitivity of hydrological models to estimate runoff and erosion, especially in tropical watersheds. Rowland (1993) further contends that this spatial variability of tropical soils may in part be the reason for recognizing about twenty-two broad soil units for tropical soils in the FAO Legend of soil map of the world. Thus spatial variability is an unresolved problem in the management of tropical soils.

\section{Similar Media Concept}

Data on soil hydraulic and hydrologic parameters require large data sets in order to make meaningful inferences and recommendations for field water management. However, handling, manipulation and analyses of such large, complex, variable and fast moving data sets are difficult to process for decision making. This requires appropriate analytical techniques to be used to their extent. Such techniques involve pedometrics, a discipline in soil science concerned with the development of mathematical and statistical methods for handling variable soil properties and processes for robust and reliable conclusions (Lark, 2006). Examples of such effective techniques include similar media scaling, fractal dimension and Geostatistics, which have been developed to address these challenges to improve the effectiveness and accuracy in the description of large soil hydraulic and hydrologic data for effective decision-support information in soil hydrology.

The application of soil physics using the similar media theory to deal with the problem of spatial variability in soil hydraulic properties was proposed by Miller and Miller (1956), and several workers (e.g. Peck et al., 1977; Warrick et al., 1977; Jury et al., 1987; Bonsu and Laryea, 1989; Zavattaro et al., 1999; Zhu and Mohanty, 2006; Tuffour et al., 2014) have successfully used the theory to describe the spatial variability of field and laboratory measured soil hydraulic properties. Scaling theory based on the similar media concept, provides a basis for representing soil spatial variability in terms of a single stochastic variable, the scaling factor, which is related to the microscopic characteristic length of the soil. Two soils are considered to be similar when they only differ with respect to their internal microscopic geometries. It is, therefore, assumed that the heterogeneity in the soil hydraulic properties is represented by a scaling factor, which is considered as recognition of a spatially stochastic variable.

The application of similar media concept involves developing scaling factors, which are simple conversion factors relating the characteristics of one system to corresponding characteristics of another (Tillotson and Nielsen, 1984). The use of the similar media concept has offered scope for coalescing variable field infiltration measurements of a given location into a single representative curve as demonstrated by Sharma and Luxmoore (1979), Sharma et al. (1980), Young and Price (1981), Wells et al. (1986) and Tuffour et al. (2014). The use of similar media concept in studying field heterogeneity with regard to variable field measured infiltration curves is still in vogue. However, the dimensional validity of the similar media theory proposed by Warrick et al. (1985) is inappropriate, in that, the characteristic time scale $\left(t_{c}\right)$ has dimension of time per distance $[\mathrm{T} / \mathrm{L}]$, hence, defining the scaled time as $\mathrm{t} / t_{c}$ yields a dimension of distance [L] which is a dimension for space, but not for time. Similarly, Wu and Pan (1997) used a characteristic infiltration equation $\left(i_{c}\right)$, which when dimensionally analyzed, is equal to the steady state infiltrability $\left(K_{o}\right)$, and contains no scaling factor $(\alpha)$. In this regard, these parameters have to be reduced in the most efficient form using dimensional analysis under the scaling laws.

\section{Scaling Theory}

Invariably, the scaling factors used in scaling variable infiltration curves have been derived from sorptivity $(\mathrm{S})$ and steady state infiltrability $\left(K_{o}\right)$, which are respectively the first and the second terms of the truncated Philip's (1957) infiltration equation:

$$
I=S t^{1 / 2}+K_{o} t
$$

Sharma et al. (1980) were of the view that both $S$ and $K_{o}$ were needed in order to develop appropriate scaling factors for measured field infiltration. On the contrary, Bonsu (1997) noted that using both $S$ and $K_{o}$ to develop scaling factors for field infiltration measurement of a highly variable Alfisol of the semi-arid tropics in India partitioned the scaled infiltration curves into two dissimilar curves. Zavattaro et al. (1999) have used the similar media concept to derive scaling factors from the steady state infiltrability $K_{o}$ alone. They used the scaling factors to study spatial dependence of $K_{o}$ using variogram analysis which showed a clear dependence of the scaling factors on distance. The work of Zavattaro et al. (1999), therefore, demonstrates how scaling factors derived from $K_{o}$, using the similar media theory, can be combined with Geostatistics to describe spatial variability in soil of a given site. In this study, the steady state infiltrability 
$\left(K_{o}\right)$ and the laboratory-column measured saturated hydraulic conductivity $\left(K_{S}\right)$ were used in place of the field saturated hydraulic conductivity $\left(K_{f s}\right)$ to scale the infiltration rate measurements. In recent times, the use of $K_{o}$ in place of $K_{f s}$ is becoming popular because of the relatively longer time and tedium required to measure field $K_{f s}$. For example, Wu and Pan (1997), Wu et al. (1999) and Zavattaro et al. (1999) have all used $K_{o}$ instead of $K_{f s}$ to scale infiltration. However, the limitation that $K_{o}$ is slightly lower than $K_{f s}$ is well appreciated. However, the use of $K_{s}$ will be much more convenient in terms of time and ease of computation (Elrick et al., 2002). Based on the Similar Media Concept, Warrick et al. (1977) evoked a relationship of the form:

Where,

$$
K_{i}=\alpha_{i}^{2} K^{*}
$$

$K_{i}=$ Steady state infiltrability and saturated hydraulic conductivity of location $i$

$K^{*}=$ Scaled mean steady state infiltrability and saturated hydraulic conductivity

$\alpha_{i}=$ Scaling factor for location $i$.

Equation (2) can be re-written as:

$$
\sqrt{K_{i}}=\alpha_{i} \sqrt{K^{*}}
$$

By convention:

$$
\sqrt{K^{*}}=i / n \sum_{n=1}^{n} \sqrt{K_{i}}
$$

In equation (4) $n$ is the number of sample spots. By combining equations (3) and (4), a relationship of the form given in equations (5) is obtainable.

$$
\sqrt{K_{i}}=\alpha_{i} / n \sum_{i=1}^{n} \sqrt{K_{i}}
$$

Therefore, from equation (5) it is seen that:

$$
n \sqrt{K_{i}}=\alpha_{i} \sum_{i=1}^{n} \sqrt{K_{i}}
$$

Hence the scaling factor $\alpha_{i}$ for location $i$ is defined as:

$$
\alpha_{i}=\frac{n \sqrt{K_{i}}}{\sum_{i=1}^{n} \sqrt{K_{i}}}
$$

By dimensional analysis, the characteristic infiltration equation $i_{c}$ is defined as:

$$
i_{c}=\frac{\alpha K_{i}}{\theta_{s}-\theta_{a}}
$$

Where,

$\theta_{s}=$ Saturated volumetric water content

$\theta_{a}=$ Initial water content of the soil before the infiltration measurement.

Therefore, the scaled infiltration rate, $i^{*}$ is defined as:

$$
i^{*}=i / i_{c}
$$

Where $i$ is the measured infiltration rate, and $i_{c}$ is obtained from equation (8). The scaled time $t^{*}$ is also defined as:

$$
t^{*}=\alpha t
$$

Where $t$ is the measured time, and $\alpha$ is the scaling factor.

The objective of this study was to propose a technique of using dimensional analysis as a tool to evaluate the reasonableness of the similar media theory. 


\section{Material and Methods}

\section{Study areas}

Field infiltration studies were carried out in the Department of Horticulture and Plantations Section of the Department of Crop and Soil Sciences, Faculty of Agriculture, Kwame Nkrumah University of Science and Technology, Ghana. Infiltration measurements were conducted using a single ring infiltrometer of diameter of $30 \mathrm{~cm}$ and a height of $30 \mathrm{~cm}$. The measurements were carried out during the dry periods of early September, 2016 to January, 2017. The sites chosen for the measurements were Turf grass field (located in the Department of Horticulture, Cocoa plantation (Plantation crops section of the Department of Crop and Soil Sciences) and Pastureland (Beef and Dairy Cattle Research Station), where spatial variability was anticipated because of expected worm activity and the presence of dead root channels. The soils were classified as Ofin series (Stagni-Dystric Gleysol), Kumasi series (Plinthi Ferric Acrisol or Typic Plinthustult) and Asuansi series (Plinthic Acrisol) in the horticulture, arable and grazed fields, respectively (FAO/UNESCO, 1990; Soil Survey Staff, 1998).

\section{Field infiltration measurements}

The infiltration measurements were carried out in 15 spots selected randomly in a grid of $10 \mathrm{~m}$ apart in each of the fields. The infiltrometer was worked into the soil using a template and a hammer to a depth of $10 \mathrm{~cm}$, leaving a height of $20 \mathrm{~cm}$ protruding above the soil surface. The surface of the soil in the infiltrometer was lightly covered with dead grass mulch to prevent soil surface disturbance when the soil surface in the infiltrometer was instantaneously ponded with water. A marker of $5 \mathrm{~cm}$ inserted in the center of the cylinder was used to maintain a constant head of $5 \mathrm{~cm}$ by adding water from 1-liter plastic measuring cylinder. The volume of water that was used to maintain a constant head of $5 \mathrm{~cm}$ infiltrometer in a chosen time represented the amount of water that entered the soil at the stipulated time. Initial measurements were recorded every 30 seconds and the recording time was extended to 60, 120 and 300 seconds, as infiltration decreased over time. The infiltration measurement was carried out for a period of 60 minutes on each spot.

The cumulative infiltration amount (I) from the field measurements were computed by converting the cumulative volume of water infiltrated at each time step to depth as follows (Tuffour, 2015):

$$
I=\frac{Q}{A}
$$

where,

$Q=$ Cumulative volume of water $(\mathrm{ml}) ; 1 \mathrm{ml}=1 \mathrm{~cm}^{3}$

$A=$ Surface area of the ring, given by:

$A=\pi r^{2}$

$r=1 / 2$ Ring diameter

The cumulative infiltration amounts were plotted as a function of time on a linear scale. The slopes of the cumulative infiltration amounts taken at different time scales represented the infiltration rates. The infiltration rates were plotted against time and the steady state infiltrability obtained at a point where the infiltration rate curve became almost parallel to the time axis. Soil samples were taken to determine the initial moisture content before the infiltration measurement. The field saturated water content was assumed to approximate the total porosity of the soil (van Genuchten, 1980).

Saturated hydraulic conductivity

The saturated hydraulic conductivity was determined using the falling head permeameter on laboratory soil columns as described by Bonsu and Laryea (1989) and Tuffour (2015). Soil samples in cores were collected from the $0-20 \mathrm{~cm}$ depth from each spot in the field and soaked for 24 hours in water until they were completely saturated. The soil core was placed on a large plastic container with perforated bottom filled with fine gravel. The system was placed in a sink and water was gently ponded over the surface of the soil core to give hydraulic head in the extended cylinder. The fall of the hydraulic head $h \_t$ at the soil surface was measured as a function of time $t$ using a water manometer with a 5 meter scale. Saturated hydraulic conductivity was then calculated by the standard falling head equation as:

$$
K_{s}=\left(\frac{\mathrm{a} L}{A t}\right) \ln \left(\frac{h_{o}}{h_{t}}\right)
$$

where,

$\mathrm{a}=$ Surface area of the cylinder $\left[\mathrm{L}^{2}\right]$ 
$A=$ Surface area of the soil [ $\left.\mathrm{L}^{2}\right]$

$h_{o}=$ Initial hydraulic head [L]

$L=$ Length of the soil column [L]

$h_{t}=$ Hydraulic head after a given time $t[\mathrm{~L}]$

By rewriting equation (11), a regression of $\ln \left(\frac{h_{o}}{h_{t}}\right)$ on $t$ with slope $\mathrm{b}=K_{s}\left(\frac{A}{L \mathrm{a}}\right)$ was obtained. Bases on the assumption that a $=A$ in this particular case, $K_{S}$ was simply calculated as:

$$
K_{s}=\mathrm{b} L
$$

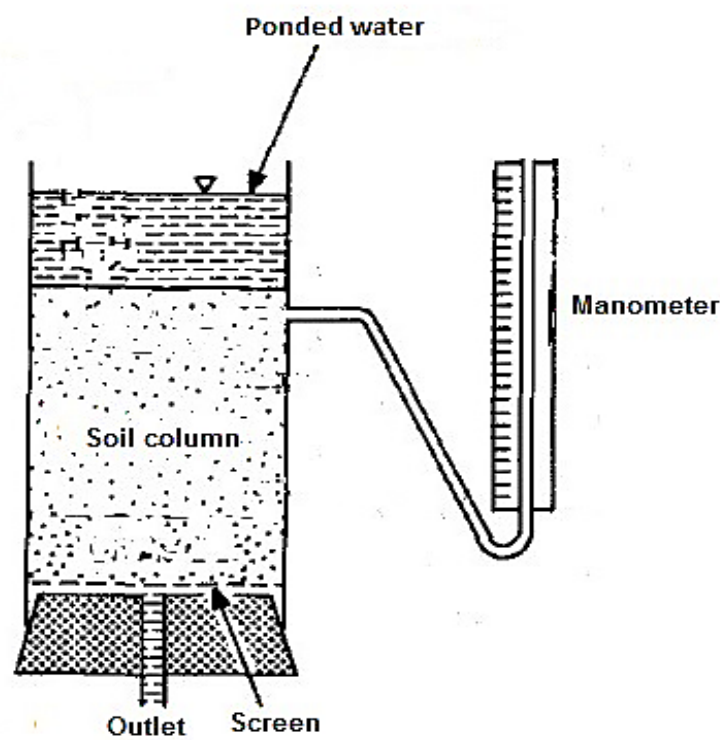

Figure 1. Laboratory setup for the determination of saturated hydraulic conductivity (Modified from Tuffour, 2015)

\section{Statistical analysis}

The question of whether or not the use of $K_{S}$ in place of $K_{o}$ provides an accurate prediction of infiltration rate was addressed using correlation analyses of the scaling parameters derived from both properties. To quantitatively evaluate the performance of $K_{S}$ and $K_{o}$ in the proposed scaling method, the coefficient of regression $\left(\mathrm{R}^{2}\right)$ of the reference curve was computed. The computation of the scaling parameters and plotting of the graphs were done using Microsoft EXCEL and GraphPad Prism version 6.

\section{Results and Discussion}

Some properties of the topsoil of the site used for the study are presented in Table 1 . The texture of the topsoil for the various sites were sand (in Turf grass) loamy sand (in both Cocoa plantation and Pastureland). The calculated parameters used in scaling operation are given in Tables 2. The plots of the infiltration rates as a function of time for all 15 spots in each field are illustrated in Figure 2 . Both the cumulative infiltration amount curve and the infiltration rate curve depict spatial variability among the spots used for the study.

Table 1. Soil physical properties of the experimental sites

\begin{tabular}{lccc}
\hline \multirow{2}{*}{ Soil property } & \multicolumn{3}{c}{ Experimental field } \\
\cline { 2 - 4 } & Turf grass & Cocoa plantation & Pastureland \\
\hline Sand (\%) & $89.00(3.90)$ & $86.00(2.90)$ & $83.00(3.10)$ \\
Silt (\%) & $5.30(3.50)$ & $6.70(2.20)$ & $9.00(1.80)$ \\
Clay (\%) & $5.30(3.50)$ & $7.20(1.20)$ & $7.50(2.30)$ \\
Texture & Sandy & Loamy sand & Loamy sand \\
$\rho_{b}\left(\mathrm{~g} \mathrm{~cm}^{-3}\right)$ & $1.50(0.12)$ & $1.40(0.075)$ & $1.20(0.13)$ \\
$f(\%)$ & $43.00(4.30)$ & $47.00(0.029)$ & $53.00(6.10)$ \\
$a f(\%)$ & $24.00(8.00)$ & $34.00(4.00)$ & $50.00(5.80)$ \\
$\theta_{v}(\%)$ & $20.00(6.90)$ & $12.00(3.60)$ & $4.10(2.50)$ \\
\hline
\end{tabular}

\footnotetext{
${ }^{*}$ Numbers in the parentheses represent standard deviation values; $\rho_{\mathrm{b}}=$ Bulk density; $f=$ Total porosity; $a f=$ Air-filled
} porosity; $\theta_{v}=$ Initial volumetric water content 
Table 2. Infiltration properties at the different study sites

\begin{tabular}{c|cccc|cccc|cccc}
\hline \multirow{2}{*}{ Parameter } & \multicolumn{4}{|c|}{ Turf grass } & \multicolumn{4}{c|}{ Cocoa plantation } & \multicolumn{3}{c}{ Pastureland } \\
\cline { 2 - 13 } & Min & Max & Mean & SD & Min & Max & Mean & SD & Min & Max & Mean & SD \\
\hline$S$ & 0.05 & 2.40 & 0.75 & 0.66 & 0.71 & 4.70 & 2.60 & 1.20 & 0.84 & 7.80 & 3.40 & 2.10 \\
$I$ & 0.75 & 23.00 & 9.60 & 7.80 & 5.90 & 52.00 & 33.00 & 15.00 & 16.00 & 110.00 & 44.00 & 22.00 \\
$i$ & 0.01 & 0.39 & 0.16 & 0.13 & 0.099 & 3.20 & 0.87 & 0.47 & 0.26 & 1.80 & 0.73 & 0.37 \\
$K_{o}$ & 0.01 & 0.57 & 0.20 & 0.17 & 0.12 & 0.97 & 0.62 & 0.27 & 0.27 & 1.90 & 0.76 & 0.38 \\
$K_{S}$ & 0.022 & 0.69 & 0.25 & 0.21 & 0.18 & 1.50 & 0.94 & 0.40 & 0.41 & 2.80 & 1.20 & 0.58 \\
\hline
\end{tabular}

$S\left(\mathrm{~cm} / \mathrm{min}^{1 / 2}\right)=$ Sorptivity; $I(\mathrm{~cm})=$ Cumulative infiltration amount; $i(\mathrm{~cm} / \mathrm{min})=$ Infiltration rate; $K_{S}(\mathrm{~cm} / \mathrm{min})=$ Saturated hydraulic conductivity; $K_{o}(\mathrm{~cm} / \mathrm{min})=$ Steady state infiltrability
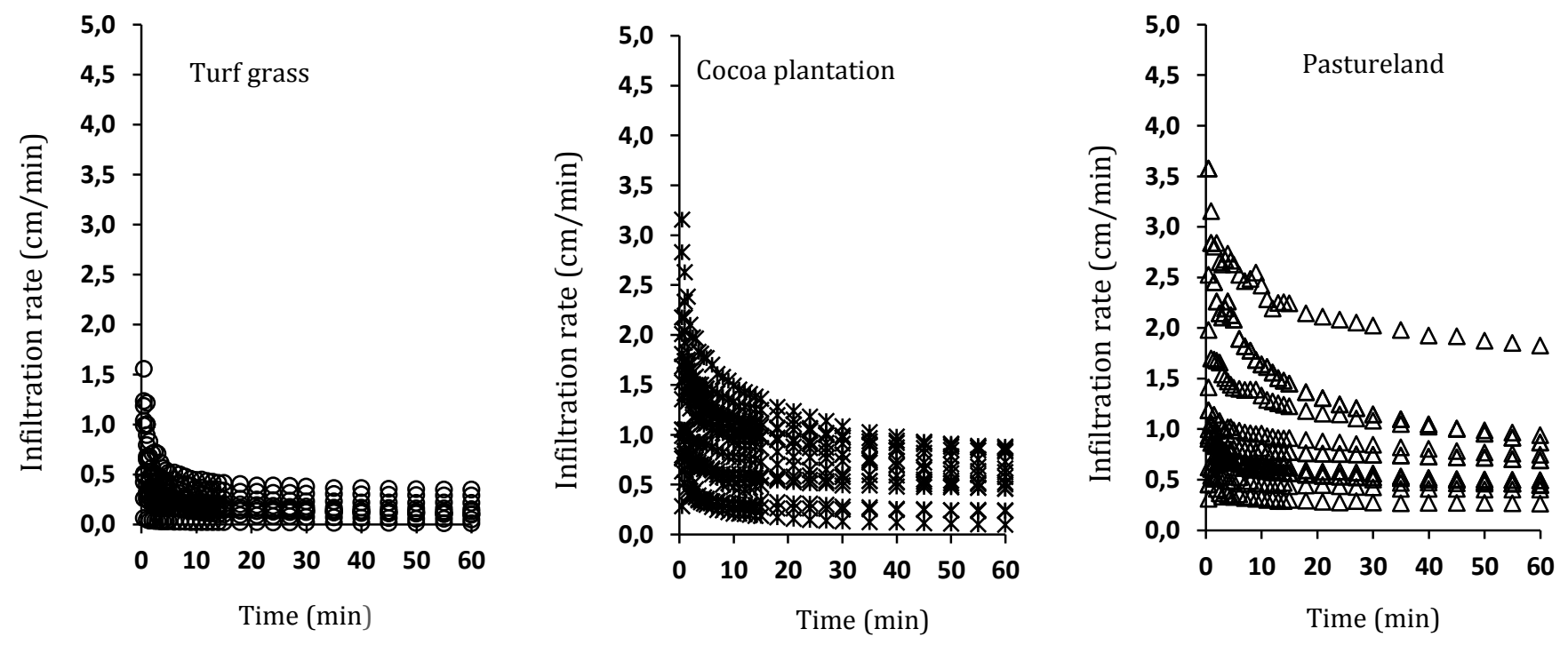

Figure 2. Variability of infiltration rate in the experimental fields

The number of scaling factors generated were too small to enable variograms to be developed to study the structure of the variability using the scaling factors as was done by Wu and Pan (1997). However, the infiltration data were enough to use scaling technique to deal with this kind of variability precisely. The range of scale factors generated for each location in the three fields follows the trends reported by various researchers (e.g. Warrick et al., 1977; Sharma and Luxmoore, 1979, Sharma et al., 1980; Bonsu and Laryea, 1989; Bonsu, 1997; Zhu and Mohanty, 2006; Tuffour et al., 2014). The very purpose of the effective (scaled) parameters obtained for this study was to show whether the behavior of the parameters in the soil could be assumed as a set of soil parameters, in order to replace the heterogeneity in the soil system by an equivalent homogeneous system (Zhu and Mohanty, 2006; Tuffour et al., 2014). With regard to this same idea, reports have shown that these parameters are site specific and there are no universal effective properties due to the great nonlinearity of soil hydraulic properties and various boundary conditions that exist under different flow states (Zhu and Mohanty, 2002; Tuffour et al., 2014). The 'equivalent' soil properties produced in this study were therefore expected to, somewhat, yield very similar water budget as the mean water budget in agreement with the soil hydraulic properties and the variation of the microtopography of the study area (Zhu and Mohanty, 2006; Tuffour et al., 2014).

The characteristic infiltration rate $\left(i_{c}\right)$ developed from $K_{o}$ and $K_{S}$, respectively, through dimensional analysis (equation 7) and used to form the dimensionless scaled infiltration rate (equation 8) was plotted against the scaled time (equation 9) as shown in Figures 3a-b.

It was observed that all the variable infiltration rates of the 15 spots in each field coalesced into a single representative curve. The level of success of the scaling exercise is evidenced by the degrees of scatter in Figures 2 and $3 a-b$, and of dispersion as shown by the standard of deviation in Tables 2 and 3 . Thus, the use of scaling factors was effective in reducing the degree of variability of infiltration rates in the different fields to produce a significant representative curve (Tuffour et al., 2014). Thus, by plotting the normalized data on a graph, a representative reference infiltration rate curve was obtained. This was expected, since the use of scaling factor is known to reduce the overall spot-to-spot variability of measured variables into unison (Vogel et al., 1991; Tuffour et al., 2014). The standard deviation (SD) values provided a means of measuring the validity of the interrelation conditions and the validity of the scaling theory. Based on the SD values $[0.25$ 
- 0.46), it is clear that the theory worked efficiently for all three fields when $K_{o}$ and $K_{S}$ were used for scaling. The nature of the graphical plots as presented in Figures 3a and b indicates a lognormal distribution of infiltration rate, implying that scaling factors are lognormally distributed (Clausnitzer et al., 1992; Kosugi and Hopmans, 1998; Tuffour et al., 2014). This, according to Tuffour et al. (2014) was based on the assumption lognormally distributed soil pore radius and random sampling of effective pore volume in the study.

Table 3. Calculated scaling parameters for the different study sites

\begin{tabular}{|c|c|c|c|c|c|c|c|c|c|c|c|c|}
\hline \multirow{2}{*}{ Parameter } & \multicolumn{4}{|c|}{ Turf grass } & \multicolumn{4}{|c|}{ Cocoa plantation } & \multicolumn{4}{|c|}{ Pastureland } \\
\hline & Min & Max & Mean & SD & Min & $\operatorname{Max}$ & Mean & SD & Min & Max & Mean & SD \\
\hline$K_{o}^{1 / 2}$ & 0.14 & 0.90 & 0.47 & 0.22 & 0.35 & 0.98 & 0.77 & 0.19 & 0.52 & 1.40 & 0.89 & 0.22 \\
\hline$\alpha K_{o}$ & 0.30 & 1.90 & 1.00 & 0.46 & 0.45 & 1.30 & 1.00 & 0.25 & 0.58 & 1.60 & 1.00 & 0.25 \\
\hline$i_{c} K_{o}$ & 0.032 & 13.00 & 1.90 & 3.20 & 0.17 & 3.70 & 2.00 & 1.20 & 0.28 & 5.40 & 1.90 & 1.30 \\
\hline$i^{*} K_{o}$ & 0.0040 & 6.97 & 0.44 & 0.52 & 0.23 & 1.40 & 0.45 & 0.18 & 0.26 & 2.30 & 0.65 & 0.25 \\
\hline$t^{*} K_{o}$ & 0.13 & 89.54 & 14.13 & 16.30 & 0.23 & 77.00 & 17.00 & 18 & 0.29 & 94.00 & 17.00 & 18.00 \\
\hline$K_{s}^{1 / 2}$ & 0.17 & 1.10 & 0.58 & 0.27 & 0.42 & 1.20 & 0.94 & 0.24 & 0.64 & 1.70 & 1.10 & 0.27 \\
\hline$\alpha K_{s}$ & 0.30 & 1.90 & 1.00 & 0.46 & 0.19 & 1.50 & 0.99 & 0.43 & 0.58 & 1.60 & 1.00 & 0.25 \\
\hline$i_{c} K_{s}$ & 0.048 & 19.00 & 2.80 & 4.80 & 0.11 & 6.40 & 3.10 & 2.20 & 0.41 & 8.10 & 2.80 & 2.00 \\
\hline$i^{*} K_{S}$ & 0.15 & 115.00 & 17.00 & 20.00 & 0.13 & 7.10 & 0.49 & 0.62 & 0.17 & 1.50 & 0.43 & 0.17 \\
\hline$t^{*} K_{\mathrm{s}}$ & 0.0027 & 4.60 & 0.29 & 0.35 & 0.096 & 93.00 & 18.00 & 20.00 & 0.29 & 94.00 & 17.00 & 18.00 \\
\hline
\end{tabular}

$\alpha K_{o}=$ Scaling factor from $K_{o} ; i_{c} K_{o}(\mathrm{~cm} / \mathrm{min})=$ Characteristic infiltration rate from $K_{o} ; i^{*} K_{o}=$ Scaled infiltration rate from $K_{o} ; t^{*} K_{o}(\mathrm{~min})=$ Scaled time from $K_{o} ; \alpha K_{S}=$ Scaling factor from $K_{S} ; i_{c} K_{s}(\mathrm{~cm} / \mathrm{min})=$ Characteristic infiltration rate from $K_{s} ; i^{*} K_{s}=$ Scaled infiltration rate from $K_{s} ; t^{*} K_{s}(\mathrm{~min})=$ Scaled time from $K_{s}$

Although the infiltration rate values fall within a wide range as revealed by the descriptive statistical analysis (Table 2; Figure 2). Figures 3a and $b$ indicate that the scaled infiltration rates coalesced into a unified curve and could be well described by a logarithmic model of the form presented in equation 13:

$$
i^{*}=-m \ln \left(t^{*}\right)+i_{i}^{*}
$$
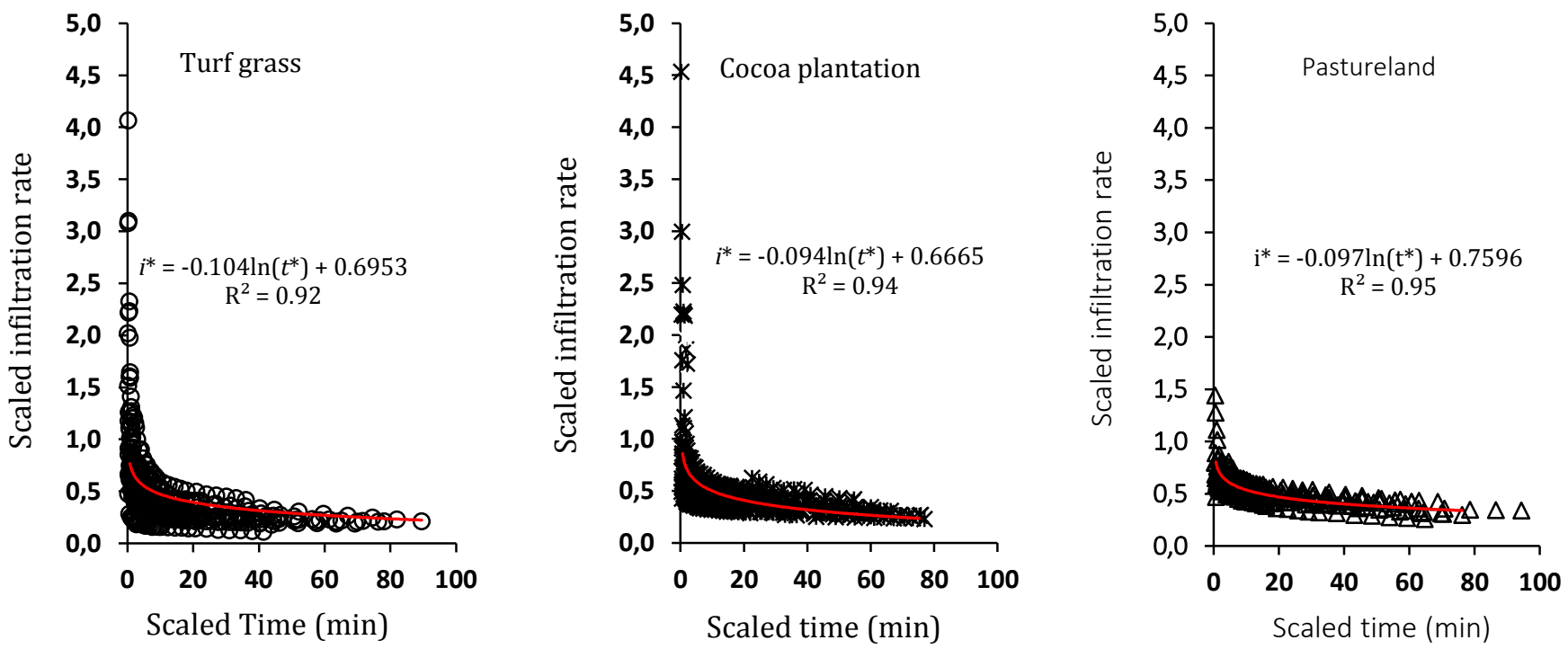

Figure 3a. Scaled infiltration rate curves from $K_{o}$ in the experimental fields

The parameters $m$ and $i_{i}^{*}$ are empirical fitting parameters describing the scaled infiltration rate $\left(i^{*}\right)$ when scaled time $\left(t^{*}\right)$ is zero. Additionally, the $\mathrm{R}^{2}$ of the representative curves lends credence of $94-99 \%$ to the reliability of this equation, which presents a linear-log fit between the dimensionless scaled infiltration rate with respect to time. Thus, a good agreement exists using a single solution to approximate the infiltration rate of the experimental fields. A general comparison of the transformed data (Figures 3a,b) indicates that, the scaling performance was high with $K_{o}$ than $K_{s}$ in both fields, as evidenced by the $\mathrm{R}^{2}$ values. The poor performance of $K_{o}$ relative to $K_{S}$ in scaling could be justified by the invalidity and over simplification of the assumption of complete field saturation at steady state during infiltration as defined in the Philip's equation. However, from Table 4, the various scenarios (i.e., scaling under $K_{o}$ and $K_{S}$ ) show that the scaling parameters are nearly invariant with limited scattering about the mean. Hence, assuming that the two 
scenarios are held for a range of soils and selected initial conditions, the proposed scaling method can be generalized to numerous other cases in this range leading to approximations of the similar media theory. This study demonstrates that scale factors developed through the similar media theory is a strong tool to equally deal with spatial variability of field infiltration measurements. However, in developing the characteristic infiltration rate and the characteristic time scale equations, dimensional analysis should be employed to ensure their dimensional validity.
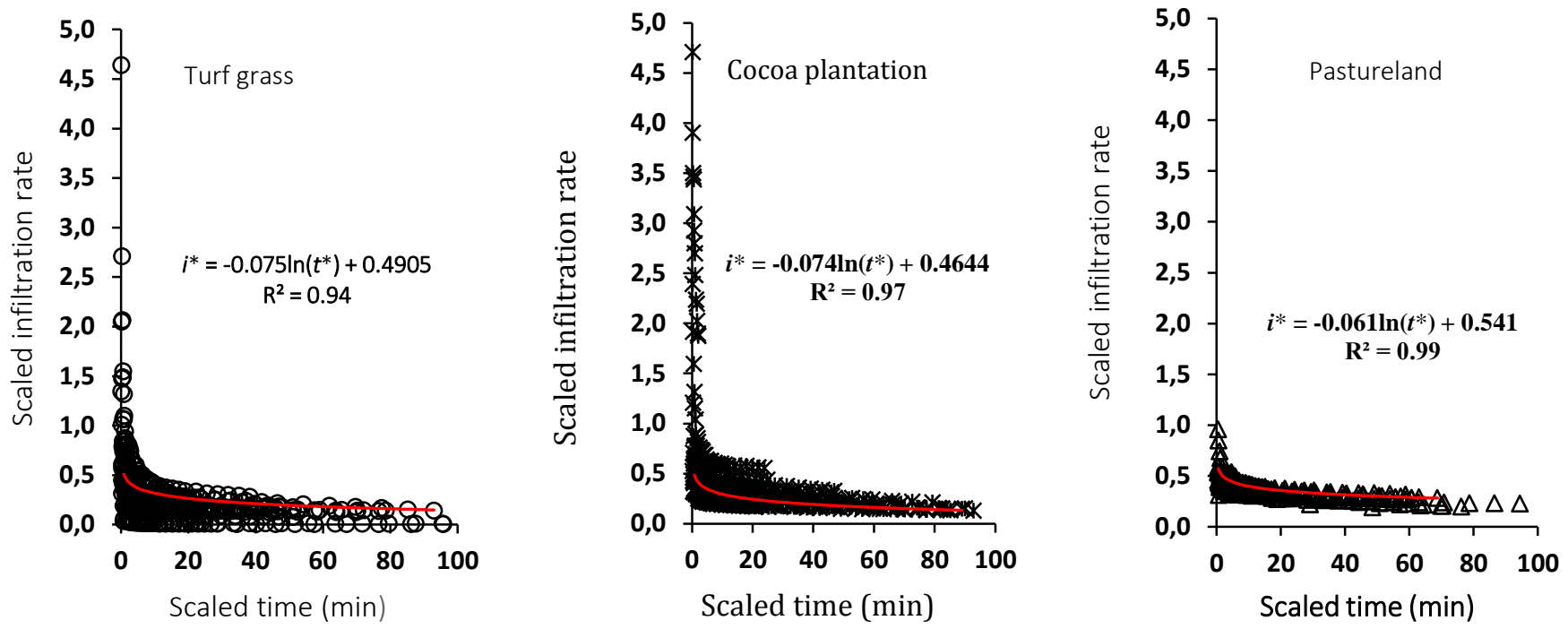

Figure 3b. Scaled infiltration rate curves from $K_{S}$ in the experimental fields

Effectively, any characteristic scaling equation developed from the similar media theory that contains no scaling factor $(\alpha)$ cannot be said to have evolved from the similar media theory. Since in the similar media theory, $\alpha$ is the controlling element, it is imperative that any characteristic equation developed to be used in the scaling operation must contain $\alpha$. The ability of a scaled equation supposedly to have been developed from the similar media concept without the incorporation of $\alpha$ to successfully scale could be fortuitous because of its deviation from the original concept of similar media theory. The original view of Sharma et al. (1980) that both sorptivity and steady state infiltrability are required in order to obtain successful scaled infiltration might not be totally correct in reference to the work of $\mathrm{Wu}$ and Pan (1997), Zavattaro et al. (1999) and the present work.

The Pearson correlation coefficients are given in Table 4. Notice a very good correspondence between scaling parameters obtained from $K_{o}$ and $K_{S}$ in all three experimental fields (Table 4) as revealed by the correlation coefficient $(r)$ and the $p(0.05)$ value. Analysis of both hydraulic parameters $\left(K_{o}\right.$ and $\left.K_{S}\right)$ showed that estimation of infiltration rate and scaling parameters can be obtained with far less effort and information when $K_{S}$ is employed. It is therefore, not necessary to differentiate the contribution of $K_{O}$ to infiltration rate from that of $K_{S}$.

Table 4. Summary of Pearson correlation between scaling parameters from $K_{o}$ and $K_{S}$

\begin{tabular}{lllll}
\hline \multirow{2}{*}{ Experimental field } & Correlated parameters & $r$ & \multicolumn{2}{c}{ tConfidence interval (95\%) } \\
\cline { 4 - 5 } Turf grass & $i^{*} K_{o}$ vs $i^{*} K_{s}$ & 0.99 & 0.97 & Upper limit \\
& $t^{*} K_{o}$ vs $t^{*} K_{s}$ & 1.00 & 0.98 & 0.99 \\
& $\alpha K_{o}$ vs $\alpha K_{s}$ & 0.99 & 0.98 & 0.99 \\
& $i_{c} K_{o}$ vs $i_{c} K_{s}$ & 1.00 & 0.99 & 1.00 \\
& & & & 0.97 \\
Cocoa plantation & $i^{*} K_{o}$ vs $i^{*} K_{s}$ & 0.96 & 0.96 & 0.98 \\
& $t^{*} K_{o}$ vs $t^{*} K_{s}$ & 0.98 & 0.97 & 0.99 \\
& $\alpha K_{o}$ vs $\alpha K_{s}$ & 0.99 & 0.97 & 1.00 \\
& $i_{c} K_{o}$ vs $i_{c} K_{s}$ & 1.00 & 0.99 & 0.98 \\
& & & & 1.00 \\
Pastureland & $i^{*} K_{o}$ vs $i^{*} K_{s}$ & 0.99 & 0.97 & 1.00 \\
& $t^{*} K_{o}$ vs $t^{*} K_{s}$ & 1.00 & 0.99 & 0.99 \\
\hline & $\alpha K_{o}$ vs $\alpha K_{s}$ & 0.99 & 0.98 & 0.98 \\
$i_{c} K_{o}$ vs $i_{c} K_{S}$ & 1.00 & & &
\end{tabular}

${ }^{\dagger} p(0.05)=<0.0001$ 
The scaling factor $(\alpha)$, characteristic infiltration rate $\left(i_{c}\right)$ and the scaled infiltration rate $\left(i^{*}\right)$ derived from $K_{o}$ and $K_{s}$ for the sites were almost identical and indistinguishable from each other as evidenced by the close match of scaling parameters obtained, in spite of the different soil hydraulic parameters that were employed in the scaling analyses. This could be as a result of the high dependency of the soil hydraulic properties on soil texture and structure which are major components in pedotransfer functions (PTFs). It is therefore imperative to know that the observed positive relationships between the $K_{o}-K_{S}$ scaling parameters were not just artifacts of correlations. Furthermore, the observed positive correlations were all linear. The uncertainties of the scaling parameters were of the same order of magnitude in both fields

\section{Conclusion}

Scaled infiltration rates from both steady state infiltrability $\left(K_{o}\right)$ and saturated hydraulic conductivity $\left(K_{s}\right)$ were found to be nearly invariant for the three study areas. This study showed that scaling factors derived from $K_{o}$ and $K_{S}$ can each be employed successfully to scale variable infiltration rates in soils. However, scaling was found to be more sensitive to $K_{o}$ than $K_{s}$. Thus, it is possible to describe the hydraulic functions of all soils by a reference soil by means of a single scaling factor assigned to each soil. Generally, the observations made in the study suggest that the proposed scaling method can be successfully applied for coarse-textured soils provided that the initial profile is not deeply wetted. Furthermore, the ability of a characteristic equation to scale variable infiltration using the similar media theory must always be verified through dimensional analysis to prove its authenticity.

\section{References}

Berndtsson, R., Larson, M., 1987. Spatial variability of infiltration in a semi-arid environment. Journal of Hydrology $90(1-$ 2): $117-133$.

Bonsu, M., 1997. Scaling infiltration using parameters of Philip infiltration equation. Journal of Applied Science and Technology 2(1-2): $1-6$.

Bonsu, M., Lal, R., 1982. Hydrological properties of some Alfisols of Western Nigeria: A comparison of field and laboratory methods. Nigerian Journal of Soil Science 3: $101-119$.

Bonsu, M., Laryea, K.B., 1989. Scaling the saturated hydraulic conductivity of an alfisol. European Journal of Soil Science 40(4): $731-742$.

Clausnitzer, V., Hopmans, J.W., Nielsen, D.R., 1992. Simultaneous scaling of soil water retention and hydraulic conductivity curves. Water Resources Research 28(1): $19-31$.

Elrick, D.E., Angulo-Jaramillo, R., Fallow, D.J., Reynolds, W.D., Parkin, G.W., 2002. Infiltration under constant head and falling head conditions. In: Environmental Mechanics: Water, Mass and Energy Transfer in the Biosphere. Raats, P.A.C., Smiles, D., Warrick, A.W. (Eds.). Geophysical Monograph Series Vol 129, American Geophysical Union, USA. pp. $47-53$.

Jury, W.A., Russo, D., Sposito, G., 1987. The spatial variability of water and solute transport properties in unsaturated soil: II. Scaling models of water transport. Hilgardia 55(4): $33-57$.

Kosugi, K., Hopmans, J.W., 1998. Scaling water retention curves for soils with lognormal pore size distribution. Soil Science Society of America Journal 62(6): 1496 - 1505.

Lark, R.M. 2006. Soil properties and Pedometrics. Land Use and Land Cover, from Encyclopedia of Life Support Systems (EOLSS), Developed under the Auspices of the UNESCO. Oxford: EOLSS Publishers. Available at [Access date : 18.01.2018]: https://www.eolss.net/Sample-Chapters/C19/E1-05-07-03.pdf

Miller, E.E., Miller, R.D. 1956. Physical theory for capillary flow phenomena. Journal of Applied Physics 27: 324.

Philip, J.R., 1957. The theory of infiltration. 4: Sorptivity and algebraic infiltration equations. Soil Science 84(3): 257 264.

Rowland, J.R.J., 1993. Dryland Farming in Africa. The Macmillan Press Ltd. London, England. 336p.

Sharma, M.L., Gander, G.A., Hunt, C.G., 1980. Spatial variability of infiltration in a watershed. Journal of Hydrology 45(12): $101-122$.

Sharma, M.L., Luxmoore, R.J. 1979. Soil spatial variability and its consequences on simulated water balance. Water Resource Research 15(8): 1567-2573.

Tillotson, P.M., Nielsen, D.R.,1984. Scaling factors in soil science. Soil Science Society of America Journal 48(5): 953 - 959.

Tuffour, H.O., 2015. Physically based modelling of water infiltration with soil particle phase. Kwame Nkrumah University of Science and Technology, Department of Crop and Soil Sciences, PhD. Thesis, Kumasi, Ghana.

Tuffour, H.O., Abubakari, A., Bashagaluke, J.B., Djagbletey, E.D., 2016. Mapping spatial variability of soil physical properties for site-specific management. International Research Journal of Engineering and Technology 3(2): 149 $-163$.

Tuffour, H.O., Bonsu, M., 2015. Application of green and ampt equation to infiltration with soil particle phase. Interna $\neg$ tional Journal of Scientific Research in Agricultural Sciences 2(4): 76 - 88. 
Tuffour, H.O., Bonsu, M., Khalid, A.A., Adjei-Gyapong, T., 2014. Scaling approaches to evaluating spatial variability of saturated hydraulic conductivity and cumulative infiltration of an acrisol. International Journal of Scientific Research in Knowledge 2(5): 224 - 232.

Tuffour, H.O., Bonsu, M., Khalid, A.A., Adjei-Gyapong, T., Atakora, W.K., 2013. Evaluation of spatial variability of soil organic carbon and pH in an uprooted oil palm field. Indian Journal of Applied Agricultural Research 1(1): 69 - 86.

van Genuchten, M.Th., 1980. A closed-form equation for predicting the hydraulic conductivity of unsaturated soils. Soil Science Society of America Journal 44(5): 892-898.

Vogel, T., Cislerova, M., Hopmans, J.W., 1991. Porous media with linearly variable hydraulic properties. Water Resources Research 27(10): 2735 - 2741.

Warrick, A.W., Lomen, D.O., Yates, S.R. 1985. A generalized solution to infiltration. Soil Science Society of America Journal 49(1): $34-38$.

Warrick, A.W., Mullen, G.J., Nielsen, D.R. 1977. Scaling field-measured soil hydraulic properties using a similar media concept. Water Resource Research 13(2): 355 - 362.

Webster, R., 1985. Quantitative spatial analysis of soil in the field. In: Advances in Soil Science. Stewart, B.A. (Ed.). Springer-Verlag Inc. New York, USA. pp. 1-70.

Wells, L.G., Ward, A.D., Moore, I..D., Philips, R.E., 1986. Comparison of four infiltration models in characterizing infiltration through surface mine profiles. Transactions of ASAE 29(3): 785 - 793.

Wu, L., Pan, L., Mitchell, J., Sanden, B., 1999. Measuring saturated hydraulic conductivity using a generalized solution for single-ring infiltrometers. Soil Science Society of America Journal 63(4): 788 - 792.

Young, E.G., Price, R.I., 1981. Scaling of infiltration behavior in dissimilar porous materials. Water Resource Research 17(4): $1065-1070$.

Zavattaro, L., Jarvis, N., Persson, L., 1999. Use of similar media scaling to characterize spatial dependence of near saturated hydraulic conductivity. Soil Science Society of America Journal 63(3): 486 - 492.

Zhu. J., Mohanty, B.P., 2002. Spatial averaging of van genuchten hydraulic parameters for steady-state flow in heterogeneous soils. Vadose Zone Journal 1(2): 261 - 272.

Zhu. J., Mohanty, B.P., 2006. Effective scaling factor for transient infiltration in heterogeneous soils. Journal of Hydrology $319(1-4): 96-108$ 